\title{
Sensory-specific satiety is unaffected by manipulations of flavour intensity
}

Citation for published version (APA):

Havermans, R. C., Geschwind, N., Filla, S., Nederkoorn, C., \& Jansen, A. T. M. (2009). Sensory-specific satiety is unaffected by manipulations of flavour intensity. Physiology \& Behavior, 97, 327-333. https://doi.org/10.1016/j.physbeh.2009.02.030

Document status and date:

Published: 01/01/2009

DOI:

10.1016/j.physbeh.2009.02.030

Document Version:

Publisher's PDF, also known as Version of record

Document license:

Taverne

Please check the document version of this publication:

- A submitted manuscript is the version of the article upon submission and before peer-review. There can be important differences between the submitted version and the official published version of record.

People interested in the research are advised to contact the author for the final version of the publication, or visit the DOI to the publisher's website.

- The final author version and the galley proof are versions of the publication after peer review.

- The final published version features the final layout of the paper including the volume, issue and page numbers.

Link to publication

\footnotetext{
General rights rights.

- You may freely distribute the URL identifying the publication in the public portal. please follow below link for the End User Agreement:

www.umlib.nl/taverne-license

Take down policy

If you believe that this document breaches copyright please contact us at:

repository@maastrichtuniversity.nl

providing details and we will investigate your claim.
}

Copyright and moral rights for the publications made accessible in the public portal are retained by the authors and/or other copyright owners and it is a condition of accessing publications that users recognise and abide by the legal requirements associated with these

- Users may download and print one copy of any publication from the public portal for the purpose of private study or research.

- You may not further distribute the material or use it for any profit-making activity or commercial gain

If the publication is distributed under the terms of Article $25 \mathrm{fa}$ of the Dutch Copyright Act, indicated by the "Taverne" license above, 


\title{
Sensory-specific satiety is unaffected by manipulations of flavour intensity
}

\author{
Remco C. Havermans *, Nicole Geschwind, Sabine Filla, Chantal Nederkoorn, Anita Jansen \\ Maastricht University, Maastricht, the Netherlands
}

\section{A R T I C L E I N F O}

\section{Article history:}

Received 4 February 2009

Accepted 25 February 2009

\section{Keywords:}

Sensory-specific satiety

Flavour intensity

\begin{abstract}
A B S T R A C T
Sensory-specific satiety (SSS) refers to the decline in evaluated pleasantness of a food when consumed as compared with other unconsumed foods. In two experiments it was investigated whether SSS is sensitive to manipulations of flavour intensity. In the first experiment, 40 participants (36 women) repeatedly consumed $20 \mathrm{ml}$ of either high- (group Strong; $n=20$ ) or low-intensity (group Weak) strawberry lemonade. If flavour intensity affects SSS these two groups should differ, but both groups displayed an equal degree of SSS concerning the evaluation of taste, smell, mouth feel, appearance and prospective consumption (largest $F=1.34$ ). In Experiment 2, 60 participants ( 54 women) were randomly assigned to one of three groups of equal size and repeatedly exposed to $20 \mathrm{ml}$ lemonade that increased (group Increase) or decreased (group Decrease) in flavour intensity, or retained a given intensity with each exposure (group Same). It was investigated whether online changes in flavour intensity interfere with the development of SSS, but again these groups displayed a similar degree of SSS to the lemonade (largest $F=1.40$ ). It is concluded that manipulation of flavour intensity does not likely affect SSS.
\end{abstract}

(C) 2009 Elsevier Inc. All rights reserved.

\section{Introduction}

When a food is eaten to satiety, the subjective evaluation of the pleasantness of the appearance, smell, taste and texture of that food decreases as compared to other uneaten foods. This effect has been termed sensory-specific satiety (SSS) [1]. It has been found that SSS already occurs during consumption of a meal and it is strongest shortly after eating a food to satiety [2]. This finding implies that SSS does not require postingestive feedback. Indeed, the energy content of a food has not been found to play an important role in SSS [3,4]. Furthermore, although SSS is strongest after a food is eaten to satiety, it can also occur after eating a fixed preload [5], or even after repeatedly chewing or merely smelling a food [6,7]. Therefore, SSS can be said to be the result of repeated or more or less continuous orosensory exposure to the flavour (i.e., taste and smell) of a given food.

It has been demonstrated that with such orosensory exposure neuronal responding within the secondary gustatory cortex (i.e., the orbitofrontal cortex) decreases specifically to the exposed food. No such sensory-specific decrement in responsiveness is observed within the primary taste cortex (i.e., the rostral insular region) [8]. Rolls [8] argues that identity and intensity of a taste are processed within this area, but that the pleasantness of a given flavour is represented in the

\footnotetext{
is The authors like to thank Zata Vickers and Kees de Graaf for helpful discussions and suggestions on the topic presented in this paper.

* Corresponding author. Maastricht University, Faculty of Psychology, Clinical Psychological Science, PO Box 616, 6200 MD Maastricht, the Netherlands. Tel.: +31 433884053.

E-mail address: r.havermans@psychology.unimaas.nl (R.C. Havermans).
}

orbitofrontal region, thus implying that flavour intensity and pleasantness are processed separately. Indeed, it has been found that with the exposure to a specific food/drink the pleasantness ratings of that food/drink decreases, but intensity judgments remain relatively unchanged $[6,9]$. However, the finding that SSS does not affect the perception of flavour intensity does not preclude the possibility that, conversely, manipulating flavour intensity will affect the degree and development of SSS.

Swithers and Hall [10] found that rat pups' eating responses to a stronger, more intensely sweetened solution diminished less quickly than the eating responses to weaker solutions did, thus suggesting that more intense tastes retard SSS. Note though that this study was a habituation experiment and it is still uncertain whether SSS can be described in terms of response habituation. Essed et al. [11], recently demonstrated in a sample of young women that monotonous intake across several days of three different drinks varying in sweetness intensity led to decreased pleasantness ratings of these drinks, with the largest decrease in liking for the drink with the highest sweetness intensity. This study then seems to suggest that SSS is weakened with the consumption of less intense tastes. SSS though cannot be viewed as the mere short-term version of a monotony effect. Vickers and Holton [12], for example, demonstrated in human subjects with ad libitum consumption tests that the decline in liking of a strong tea with its consumption did not differ from the decline in liking when the participant had to consume a weak tea, suggesting that flavour intensity does not affect SSS. However, flavour intensity did affect pleasantness ratings with repeated monotonous consumption of these teas, with a larger decline in liking of the strong tea.

Overall, studies are not suggestive of an effect of flavour intensity on SSS, but considering the small number of studies directly addressing 
this research topic one may argue that the question whether flavour intensity affects SSS is still left unresolved [13]. Therefore, we investigated in a first experiment whether repeated exposure to a strong flavour versus a weak flavour leads to corresponding differences in SSS. In a second experiment, we examined whether the rate and degree of SSS are altered with repeated exposure to a flavour that changes in intensity with each exposure.

\section{Experiment 1}

To test whether flavour intensity affects both the degree and rate of SSS, participants were randomly divided into two groups of equal size: Strong or Weak. Group Strong received repeated exposure to a highintensity flavour, whereas group Weak received repeated exposure to the same flavour of low intensity. If SSS is affected by flavour intensity, one would expect to see a difference in the degree and rate of SSS between these two groups.

We preferred employing a between-subjects design, rather than a within-subject design, for several reasons. Firstly, a between-subjects design ensured that participants were not aware of the flavour intensity manipulation. Secondly, considering that the weak and strong flavours only differ in intensity and not flavour itself, there would likely be substantial generalization of SSS from the lowintensity flavour to the high-intensity flavour (and vice versa), and such a generalization effect might have seriously confounded results when having employed a within-subject design; that is, examining participants' SSS to both the weak and strong flavour. Of course, such a potential order effect might have been controlled for by counterbalancing the order of the two conditions (i.e. weak flavour-strong flavour, versus strong flavour-weak flavour), but such balancing comes at the cost of introducing variance. To otherwise limit the presumed generalization effect one might also have considered introducing a considerable time interval between the two conditions. It is unclear, however, how long such a wash-out period needs to be to completely rule out any carry-over effect between conditions. Had we still chosen to employ a within-subject design with the two conditions (weak vs. strong flavour) presented to the participants on separate days the results might also have been confounded by the introduction of a monotony effect, which - as is described in the Introduction above - is already known to be sensitive to manipulations of flavour intensity.

\subsection{Method}

\subsubsection{Participants}

Forty healthy participants were recruited among the student population of Maastricht University ( $M$ age $=22$ years; 36 women). Participants were randomly divided into two groups of equal size: group Weak, or group Strong. Prior to their participation, each participant was contacted by the experimenter to check for food allergies, diabetes or any other condition that might influence their eating behaviour or taste perception. Each participant received the instruction to refrain from eating and drinking for $2 \mathrm{~h}$ prior to participation. The study was reviewed and approved by a local ethics committee.

\subsubsection{Procedure and design}

All participants provided informed consent prior to their participation. Experimental sessions took place on weekdays at 11 AM. Participants were tested in small groups $(n=4-6)$ in a quiet research laboratory. On arrival, the participants were invited to take a seat at any of the 12 available tables. The tables were placed against the walls of the laboratory and were divided by screens into separate compartments to prevent participants from directly communicating with each other during the experiment.

Participants were served a tray of eight different foods presented in single bite size portions containing the following items: chocolate
M\&Ms (Masterfoods), crisps (Lay's Superchips, Pepsico), Dutch cheese (Goudse kaas, Albert Heijn), Dutch breakfast cake (Peijnenburg), salty cracker (TUC naturel, LU), $20 \mathrm{ml}$ milk (Campina), $20 \mathrm{ml}$ of strawberry lemonade of strong intensity, and $20 \mathrm{ml}$ of the same strawberry lemonade of weak intensity. The low-intensity lemonade contained 1 part of strawberry syrup (Albert Heijn) and 8.5 parts of water, whereas the high-intensity lemonade contained 1 part of syrup and 5.5 parts of water. According to the manufacturer, 1 part syrup per 7 parts of water would provide the best taste.

Participants were instructed to consume and evaluate each item. To rate the pleasantness of these items, participants were given a questionnaire that contained questions that all had to be answered on $100 \mathrm{~mm}$ line scales. A decrease in these ratings is thought to reflect SSS. The questionnaire contained the following questions per food item: 'How pleasurable do you find the appearance/smell/taste of item nr. ...?', 'How pleasurable does item nr. ... feel in your mouth?', and 'How much would you like to eat/drink of item nr...?', all anchored with not at all/nothing at the left, and very/very much at the right. In a similar manner, the participants were asked to indicate how intense and sweet they perceived each item to be. The order of evaluating the food items was determined randomly for each separate participant. After the participants had finished their ratings of the eight food items, their trays were collected and they were given a next tray. This tray contained eight $50 \mathrm{ml}$ plastic cups filled with $20 \mathrm{ml}$ of either the low-intensity lemonade (for group Weak) or the highintensity version (for group Strong).

Generally, when assessing SSS, participants are instructed to consume a given test food ad libitum, that is, until satiety. However, as volume affects the degree of SSS [4], for the present study it was deemed important to ensure that both groups consume an equal amount of the test drink. Further, to maximize the likelihood of participants completing the experimental procedure, we purposefully selected a relatively small total amount of the test drink for our participants to consume; that is, smaller when participants would have received the instruction to consume the test drink ad libitum. Vickers and Holton [12] for example, had their participants consume iced tea ad libitum when assessing SSS. On average, those participants drank approximately $400 \mathrm{ml}$, which is considerably more than the $160 \mathrm{ml}$ in the present experiment. Bell et al. [4] exposed their participants to fixed volumes of milkshake (low or high) to assess the effect of volume on SSS. Their low volume test drink was a $300 \mathrm{ml}$ milkshake, which is also larger than the fixed aliquot of lemonade used in the present study.

Each participant had to expose oneself to the lemonade, carefully following the instructions provided by the experimenter. During a period of $15 \mathrm{~min}$, the experimenter instructed the participants to take one cup, to look at the drink for $10 \mathrm{~s}$, to smell the drink for $10 \mathrm{~s}$, to empty the cup and experience the mouth feel for $10 \mathrm{~s}$, and finally to swallow the drink. After consumption of the third and the sixth drinks, participants were asked to evaluate the drink again (i.e., rate the pleasantness of its taste, appearance, smell, mouth feel, and rate prospective consumption). Throughout this $15 \mathrm{~min}$ signaled exposure the experimenter carefully monitored adherence to the instructions. When all eight cups had been emptied, the trays were collected. A new tray was then placed in front of each participant containing all eight food items in the same manner as prior to the signaled exposure procedure and for this post-test the participants were instructed to taste and evaluate all eight items for a second time in the same order as at the pre-test. After the second evaluation of the food items, participants were thanked and received a €10 voucher as a compensation fee.

\subsection{Results and discussion}

To be able to demonstrate a potential effect of flavour intensity on SSS requires that the participants were able to reliably assess flavour 
intensity. As all participants had to evaluate the intensity and sweetness of the two lemonades at both the pre-test and post-test, we examined this by comparing ratings of sweetness and intensity of these two lemonades with paired sample $t$-tests. At both pre-test and post-test, all participants rated the flavour of the high-intensity lemonade as more intense than the low-intensity lemonade (pre-test: $M$ difference in intensity $=13.6, t[39]=5.06, p<.001$; post-test: $M$ difference in intensity $=17.7 t[39]=8.65, p<.001$ ). Participants also consistently rated the sweetness of the high-intensity lemonade as higher than the sweetness of the low-intensity lemonade (pre-test: $M$ difference in sweetness $=15.3, t[39]=6.16, p<.001$; post-test: $M$ difference in sweetness $=17.9, t[39]=9.68, p<.001)$.

To assess the degree of SSS, we calculated the change in rating for each food item by subtracting the pre-exposure ratings from the postexposure ratings. Next, we averaged this change score for the unconsumed control food items (i.e., the items that were not consumed during the signaled exposure procedure excluding the unconsumed strawberry lemonade) to be able to compare the change in rating for the consumed lemonade versus the control food items $[3,14]$. Further, we compared the change in rating for the unconsumed lemonade with the control food items to be able to assess generalization of SSS. We made these planned comparisons with a $2 \times 3$ split plot analysis of variance (ANOVA) with the between-subjects variable Group (Strong versus Weak) and within-subject variable Type (consumed lemonade, unconsumed lemonade, or control items), and with shift in rating as the dependent variable. This analysis was conducted separately for the change in ratings of taste, appearance, smell, mouth feel and prospective consumption. Fig. 1 displays the mean change in pleasantness and prospective consumption ratings for the consumed and unconsumed lemonade, and the control food items for each group.

When comparing the change in ratings for the consumed lemonade versus the change in ratings for the control items, SSS was reflected by a main effect of Type for taste $(F[1,38]=19.03, p<.001$, $\left.\eta_{\mathrm{p}}^{2}=.33\right)$, appearance $\left(F[1,38]=11.55, p<.01, \eta_{\mathrm{p}}^{2}=.24\right)$, smell $(F[1$, $\left.38]=25.24, p<.001, \eta_{\mathrm{p}}^{2}=.41\right)$, mouth feel $(F[1,38]=15.28, p<.001$, $\left.\eta_{\mathrm{p}}^{2}=.29\right)$, and prospective consumption $(F[1,38]=28.38, p<.001$, $\left.\eta_{\mathrm{p}}^{2}=.48\right)$. As can be inferred from Fig. 1, for every dependent variable the negative shift in liking of the consumed lemonade was larger than the mean shift in liking of the unconsumed food items. However, no Group $\times$ Type interactions were found, largest $F=1.34$. In other words, no difference between the two groups was found concerning the degree of SSS.

To assess potential generalization of SSS from the test drink to the unconsumed lemonade, we first compared the change in ratings of the unconsumed lemonade with the change in ratings for the control items. This rendered a main effect of Type for the ratings of taste ( $F[1$, $\left.38]=23.18, p<.001, \eta_{\mathrm{p}}^{2}=.38\right)$, smell $(F[1,38]=22.40, p<.001$, $\left.\eta_{\mathrm{p}}^{2}=.38\right)$, mouth feel $\left(F[1,38]=16.33, p<.001, \eta_{\mathrm{p}}^{2}=.30\right)$ and prospective consumption $\left(F[1,38]=23.12, p<.001, \eta_{\mathrm{p}}^{2}=.43\right)$, and a marginally significant effect for the ratings of appearance, $F(1,38)=$ $3.66, p=.064, \eta_{\mathrm{p}}^{2}=.09$. These results imply that SSS towards the test lemonade generalized to the unconsumed lemonade of different intensity. No Type $\times$ Group interactions were found (all $p$ 's $>.20$ ) with the exception of the change in pleasantness of smell ratings, $F(1$, $38)=4.18, p=.048, \eta_{\mathrm{p}}^{2}=.10$. Overall though, generalization of SSS did not appear to differ between the two groups.

Secondly, we assessed the degree of generalization of SSS from the test drink to the unconsumed lemonade of different intensity by comparing the change in ratings between these two drinks. Marginally significant effects of Type were found for the change in appearance ratings $\left(F[1,38]=2.88, p=.098, \eta_{\mathrm{p}}^{2}=.07\right)$, and for the change in ratings of prospective consumption $(F[1,38]=3.29$, $p=.079, \eta_{\mathrm{p}}^{2}=.10$ ). For the remaining dependent measures (i.e., change in taste, smell, and mouth feel pleasantness ratings) however, no such an effect was found, all $F^{\prime} \mathbf{S}<1$. A marginally significant Type $\times$ Group interaction was found for the prospective consumption ratings $\left(F[1,38]=3.29, p=.079, \eta_{\mathrm{p}}^{2}=.10\right)$, but not for the other dependent measures (all $F \mathbf{s}<1$ ). Taken together these results imply that SSS developed towards the consumed test drink to an equal degree between the two groups and that within each group this effect generalized to the unconsumed lemonade of different intensity.

Pleasantness and prospective consumption of the test drink (i.e., the strawberry lemonade) were not only assessed at pre-test and post-test, but also on two occasions during the signaled exposure procedure in between those two tests. This allowed us to examine the time course of the decrease in hedonic ratings of the test drink. Table 1 displays the mean hedonic ratings of the test drink as assessed before,

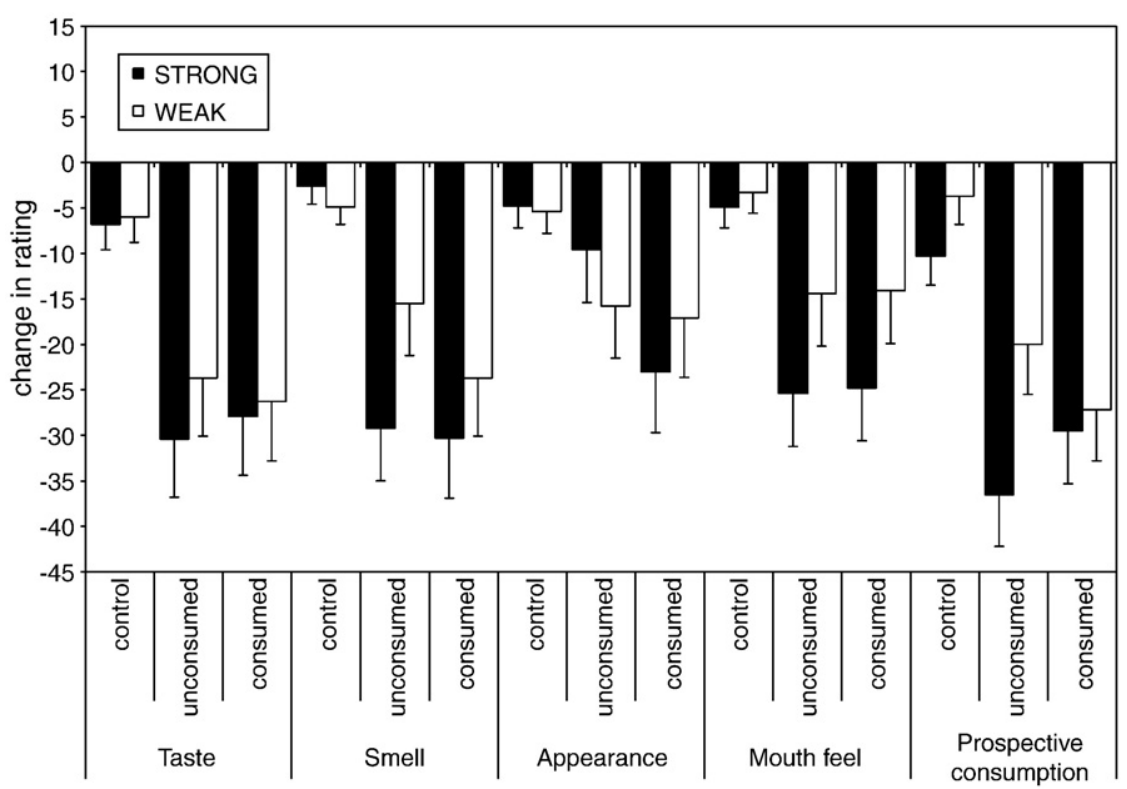

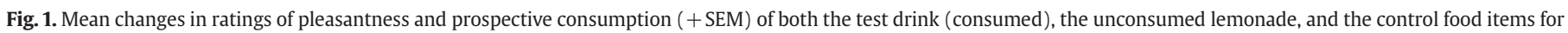
each separate group (Weak vs. Strong). 
Table 1

Mean pleasantness and prospective consumption ratings for the test drink as assessed at pre-test (assessment 1), during the signaled exposure (assessments 2 and 3), and at post-test (assessment 4), for each separate group (Weak vs. Strong).

\begin{tabular}{|c|c|c|c|c|c|c|c|c|}
\hline \multirow{2}{*}{$\frac{\text { Group }}{\text { Assessment }}$} & \multicolumn{4}{|c|}{ Weak } & \multicolumn{4}{|c|}{ Strong } \\
\hline & $\overline{1}$ & 2 & 3 & 4 & $\overline{1}$ & 2 & 3 & 4 \\
\hline Taste & 54 & 46 & 31 & 26 & 62 & 61 & 45 & 34 \\
\hline Appearance & 44 & 49 & 39 & 25 & 58 & 62 & 53 & 35 \\
\hline Smell & 55 & 46 & 35 & 30 & 65 & 52 & 47 & 35 \\
\hline Mouth feel & 60 & 57 & 46 & 45 & 67 & 63 & 52 & 42 \\
\hline Prospective consumption & 41 & 39 & 22 & 16 & 41 & 43 & 32 & 17 \\
\hline
\end{tabular}

during and directly after the signaled exposure procedure. It is conceivable that not so much the degree, but rather the onset of SSS is affected by taste intensity. Before testing this possibility, we assessed whether the two groups evaluated the pleasantness of the test drink differently at pre-test with separate $t$-tests for each dependent variable (i.e., ratings of taste, smell, appearance, mouth feel and prospective consumption). No significant differences for these measures were found between the two groups (largest $t[38]=1.73$, $p=.10$, for the pleasantness ratings of appearance).

To further test the possibility that flavour intensity affects the rate of an expected decline in hedonic ratings of the test drink, a $4 \times 2$ ANOVA was conducted with Assessment $(1,2,3$, or 4$)$ as withinsubject variable and Group (Weak versus Strong) as the betweensubjects variable, and with the pleasantness ratings and prospective consumption ratings of the lemonade as the dependent variables. An overall effect of Assessment was found on the taste ratings $(F[3,111]=$ $\left.23.44, p<.001, \eta_{\mathrm{p}}^{2}=.39\right)$, appearance ratings $(F[3,111]=17.49$, $\left.p<.001, \eta_{\mathrm{p}}^{2}=.32\right)$, smell ratings $\left(F[3,111]=19.85, p<.001, \eta_{\mathrm{p}}^{2}=.35\right)$, ratings of mouth feel $\left(F[3,111]=14.61, p<.001, \eta_{\mathrm{p}}^{2}=.28\right)$, and ratings of prospective consumption $\left(F[3,114]=30.52, p<.001, \eta_{\mathrm{p}}^{2}=.45\right)$. No Assessment $\times$ Group interaction effects were found for the pleasantness and prospective consumption ratings, largest $F=1.06$. For the evaluation of the pleasantness of the appearance of the test drink, it was found that participants in group Strong rated the pleasantness of the appearance of the drink higher than participants in group Weak, $F(1,38)=4.08, p=.05, \eta_{\mathrm{p}}^{2}=.10$. For the remaining ratings (i.e., taste, smell, mouth feel, and prospective consumption) no such main effects of Group were found, largest $F=2.58$. Apparently, there were no differences between group Weak and group Strong concerning the time course of the decline of the pleasantness and prospective consumption ratings.

\section{Experiment 2}

Results from Experiment 1 suggest that SSS is unaffected by flavour intensity; that is, the development of SSS does not appear to be retarded with exposure to more intense stimuli. To further evaluate whether SSS can be affected by flavour intensity, a second experiment was conducted involving a different type of intensity manipulation.

As SSS concerns a decline in pleasure from eaten food relative to other uneaten foods one of the main functions attributed to SSS is that it promotes the consumption of a more varied meal; that is, a meal that contains a variety of flavours and as such a wider variety in nutrients [15]. This then also means that a varied meal promotes consumption by delaying the decline in pleasantness usually associated with SSS $[16,17]$. Hetherington et al. recently conducted a study in which participants were instructed to eat popcorn until satiety [18; Experiment 1]. In three of the four conditions however, their popcorn eating was regularly interrupted by a taste test in which they had to evaluate the taste of the same popcorn, or a different snack food but with similar taste characteristics as the popcorn, or a different flavour altogether. Participants in the latter two conditions experienced a slower decrease in pleasantness ratings and also consumed more popcorn, suggesting that SSS is attenuated if consumption includes the experience of varied flavours. Within the context of the present study, the question that rises then is whether mere variety in the intensity of the test drink (i.e., the strawberry lemonade in this study) will similarly attenuate the degree and development of SSS.

\subsection{Method}

\subsubsection{Participants}

Sixty healthy participants ( $M$ age $=23$ years; 54 women) were recruited among the student population of Maastricht University. Participants were randomly assigned to one of the three groups of equal size: Increase, Same, or Decrease. All participants were contacted by the experimenter beforehand. None of the participants had participated in the previous experiment and none reported having any specific food allergies, diabetes, or any other condition that might interfere with taste perception. As for Experiment 1, each participant received the instruction to refrain from eating and drinking (excluding water) for $2 \mathrm{~h}$ prior to their participation. The study was reviewed and approved by a local ethics committee.

\subsubsection{Procedure and design}

All participants provided informed consent prior to their participation in this experiment. Experimental sessions took place on weekdays at $11 \mathrm{AM}$ and, as in Experiment 1, participants were tested in small groups $(n=4-6)$ in a quiet research laboratory. There, participants were served a tray containing four different food items presented in single bite size portions: chocolate (Milka, Kraftfoods), salty crackers (TUC, LU), $20 \mathrm{ml}$ of herbal tea served at approximately $50{ }^{\circ} \mathrm{C}$, and $20 \mathrm{ml}$ of strawberry lemonade. The lemonade contained 1 part of strawberry syrup (Albert Heijn) per 10 parts of water (1:10; group Increase), or 7 parts of water (1:7; group Same), or 4 parts of water (1:4; group Decrease). To rate the items, participants were given a questionnaire that contained questions that all had to be answered on $100 \mathrm{~mm}$ line scales. These line scales were presented on a computer screen. The questionnaire was programmed in Authorware (Macromedia) and contained the following questions per food item: 'How pleasurable do you find the appearance/smell/taste of item nr. ...?', 'How pleasurable does item nr. ... feel in your mouth?', and 'How much would you like to eat/drink of item nr. ...?', all anchored with not at all/nothing at the left, and very/very much at the right. As in Experiment 1, the participants were also asked to indicate how intense and sweet they perceived each item to be. The order in which the participants had to taste and evaluate the four food items was counterbalanced between participants within each group by means of a balanced Latin square.

After the participants had finished tasting and rating the four items, their empty trays were collected, after which the repeated exposure to the strawberry lemonade commenced. In contrast with Experiment 1, this repeated exposure procedure did not comprise the presentation of the drinks all at once. Instead, the drinks were served individually so that participants could not easily deduce any variations in flavour intensity on the basis of visual cues alone. Further, as SSS developed rapidly in Experiment 1, the number of exposures in this experiment was brought down to just five exposures (instead of eight) to the lemonade. Participants were served a cup filled with $20 \mathrm{ml}$ at fixed intervals during an approximately $10 \mathrm{~min}$ period. With each exposure, the experimenter instructed the participants to take the cup, to look at the drink for $10 \mathrm{~s}$, to smell the drink for $10 \mathrm{~s}$, to empty the cup and experience the mouth feel for $10 \mathrm{~s}$, and finally to swallow the drink.

For group Increase, the syrup-water ratio of the lemonade increased with each exposure (from $1: 9$ to $1: 8$ to $1: 7$ to $1: 6$ and to 1:5). For group Same, this ratio remained constant (i.e., 1:7). For the participants in group Decrease, the syrup-water ratio decreased with 
each exposure from 1:5 to 1:9. Participants in both groups Increase and Decrease should demonstrate less SSS than group Same does, if variety in intensity affects SSS in a similar manner as the variety in flavours appears to do.

Directly after the third exposure, all participants were asked to rate the drink once more. When all five cups had been consumed, a new tray was then placed in front of each participant containing all four food items in the same bite size portions as before the signaled exposure procedure and the participants were instructed to taste and evaluate all four items for a second time in the same order as at pretest. At this post-test, again, the intensity of the strawberry lemonade differed between groups. Participants in group Increase had to taste and evaluate lemonade that contained 1 part of syrup per 4 parts of water; participants in group Same tasted lemonade that contained 1 part of syrup per 7 parts of water; participants in group Decrease tasted lemonade that contained 1 part of syrup per 10 parts of water After this post-test, participants were thanked and received a €10 voucher as a compensation fee.

\subsection{Results and discussion}

As in Experiment 1, it was first ascertained whether the participants had been able to perceive any changes in taste intensity throughout the experiment. We tested this by examining a potential effect of Assessment $(1,2$, or 3$)$ on the intensity and sweetness ratings for each separate group. As expected, participants in group Increase progressively evaluated the test drink as more intense, $F(2,38)=9.28$, $p<.001, \eta_{\mathrm{p}}^{2}=.33$. They also progressively evaluated the test drink to be sweeter, $F(2,38)=5.31, p<.01, \eta_{\mathrm{p}}^{2}=.22$. No such effects were found for group Same and for group Decrease, largest $F=1.35$.

We assessed SSS by calculating the change in rating for each food item by subtracting the pre-exposure ratings from the post-exposure ratings and averaging this change score for the unconsumed control food items to be able to compare the change in rating for the test item versus the control items. A total of five $3 \times 2$ split plot ANOVAs with the between-subjects variable Group (Increase, Same, and Decrease) and within-subject variable Type (consumed versus unconsumed), and change in ratings of taste, appearance, smell, mouth feel and prospective consumption as the dependent variables were conducted. Fig. 2 displays the mean change in pleasantness and prospective consumption ratings for both the consumed and unconsumed foods for each separate group.

SSS was reflected by a main effect of Type on taste $(F[1,57]=19.85$, $\left.p<.001, \eta_{\mathrm{p}}^{2}=.26\right)$, appearance $\left(F[1,57]=12.01, p<.01, \eta_{\mathrm{p}}^{2}=.17\right)$, smell $\left(F[1,57]=19.85, p<.001, \eta_{\mathrm{p}}^{2}=.26\right)$, mouth feel $(F[1,57]=9.44, p<.01$, $\left.\eta_{\mathrm{p}}^{2}=.14\right)$, and prospective consumption $(F[1,57]=36.69, p<.001$, $\eta_{\mathrm{p}}^{2}=.39$ ). A Group $\times$ Type interaction effect was found concerning the appearance ratings, $F(2,57)=4.18, p<.05, \eta_{\mathrm{p}}^{2}=.13$. As can be inferred from Fig. 2, this interaction can be ascribed to the participants in group Increase who did not show a decrease in the ratings of the pleasantness of the appearance of the strawberry lemonade. With a gradual increase in taste intensity, the colour of the drink also became darker and less transparent. Apparently, a fuller and darker colour of lemonade is more liked than a more transparent watery colour. This concurs with the finding in Experiment 1 where participants liked the appearance of the strong lemonade better than the weak lemonade. For the remaining indices of SSS, no Group $\times$ Type interactions were found, largest $F=1.40$. Furthermore, no differences between groups were found, largest $F=1.43$. In sum, no systematic difference between the groups was found concerning the degree of SSS.

Analyses of the time course of the development of SSS were conducted with Assessment (1: pre-exposure, 2: during signaled exposure, and 3: post-exposure) as within-subject variable and Group (Increase, Same, and Decrease) as between-subjects variable, and the pleasantness and prospective consumption ratings of the test drink as dependent variables. An overall decrease in experienced pleasantness of the lemonade was reflected by a significant effect of Assessment for ratings of taste $\left(F[2,114]=21.62, p<.001, \eta_{\mathrm{p}}^{2}=.28\right)$, appearance $(F[2$, $\left.114]=6.77, p<.01, \eta_{\mathrm{p}}^{2}=.11\right)$, smell $(F[2,114]=13.60, p<.001$, $\left.\eta_{\mathrm{p}}^{2}=.19\right)$, and mouth feel $\left(F[2,114]=12.22, p<.001, \eta_{\mathrm{p}}^{2}=.23\right)$. Ratings of prospective consumption also decreased with repeated exposure, $F(2,114)=25.78, p<.001, \eta_{\mathrm{p}}^{2}=.31$. A significant Assessment $\times$ Group interaction was found for the ratings of appearance, $F(4,114)=2.67$, $p<.05, \eta_{\mathrm{p}}^{2}=.09$. Again, this can be ascribed to the participants in group Increase who did not demonstrate a decrease in the hedonic evaluation of the appearance of the lemonade. For the remaining pleasantness ratings and prospective consumption ratings, no such an interaction was found, largest $F=1.36$. Further, no effect of Group was found, largest $F=1.18$. Mean ratings of the test drink throughout the experiment are displayed in Table 2 for all three groups. Taken

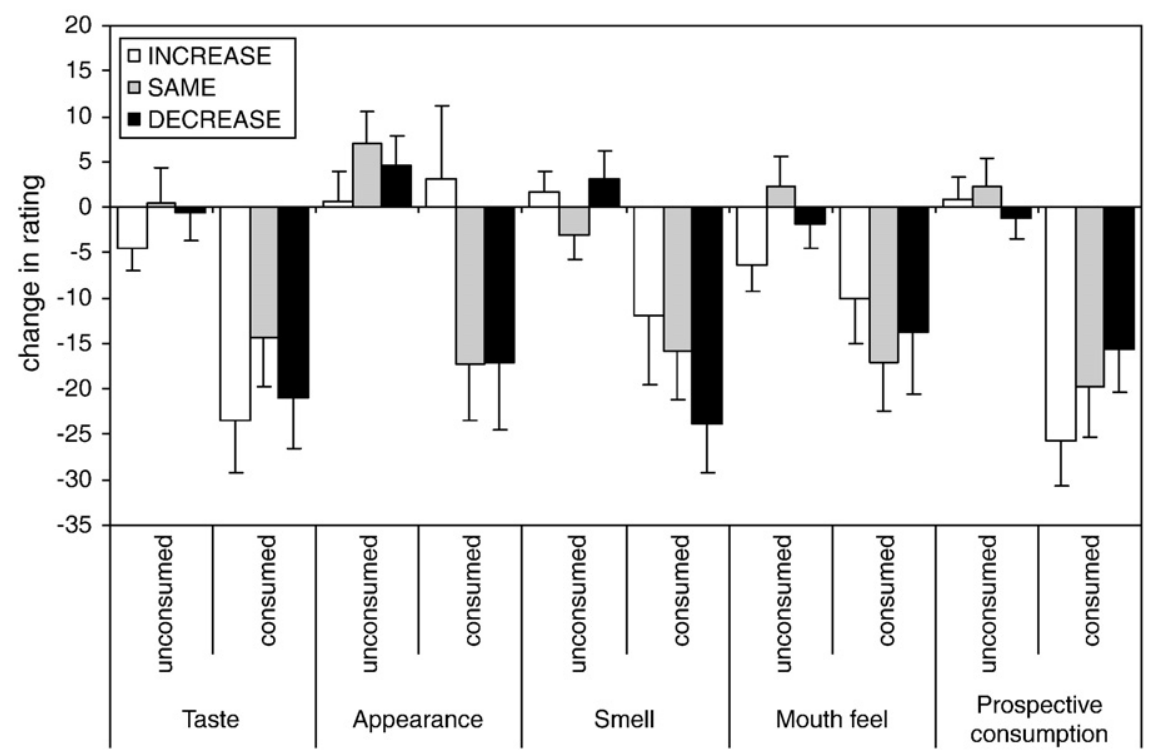

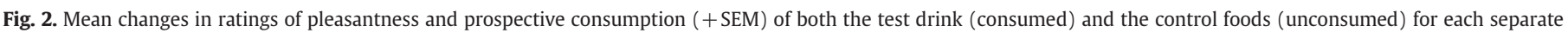
group (Increase, Same, or Decrease). 
Table 2

Mean pleasantness ratings and prospective consumption ratings as assessed at pre-test (assessment 1), during the signaled exposure (assessment 2), and at post-test (assessment 3), for each separate group (Increase, Same, Decrease).

\begin{tabular}{|c|c|c|c|c|c|c|c|c|c|}
\hline \multirow{2}{*}{$\begin{array}{l}\text { Group } \\
\text { Assessment }\end{array}$} & \multicolumn{3}{|c|}{ Increase } & \multicolumn{3}{|c|}{ Same } & \multicolumn{3}{|c|}{ Decrease } \\
\hline & $\overline{1}$ & 2 & 3 & $\overline{1}$ & 2 & 3 & $\overline{1}$ & 2 & 3 \\
\hline Taste & 68 & 56 & 45 & 62 & 55 & 47 & 55 & 53 & $\overline{34}$ \\
\hline Appearance & 51 & 60 & 55 & 60 & 52 & 43 & 50 & 58 & 33 \\
\hline Smell & 57 & 57 & 45 & 59 & 47 & 43 & 63 & 51 & 39 \\
\hline Mouth feel & 67 & 57 & 57 & 68 & 58 & 51 & 58 & 57 & 44 \\
\hline Prospective consumption & 57 & 39 & 32 & 52 & 47 & 32 & 40 & 35 & 25 \\
\hline
\end{tabular}

together, these results suggest that the development of SSS is not subject to an intensity effect.

\section{General discussion}

In the present study, in two experiments, it was tested whether manipulating flavour intensity affects SSS. In both experiments, clear indications of SSS were found; that is, subjective pleasantness derived from consuming the test food (i.e., strawberry lemonade) decreased with repeated consumption of this flavour relative to the pleasantness of other foods not repeatedly consumed. However, no effect was found of the different manipulations of flavour intensity. Taken together with previous findings showing that SSS is reflected by changes in hedonic ratings but not intensity ratings of the test food [6,9], these results support the view put forward by Rolls [8] that the identity and intensity of a taste are processed within the primary gustatory cortex separate from the evaluative reward processing of food that is thought to take place within the orbitofrontal region of the brain [see also 19].

The absence of an intensity effect in the present study is a null result and should thus be interpreted with some caution. For example, the present experimental paradigm is not a traditional SSS paradigm. A typical SSS experiment concerns the ad lib consumption of a given test food until satiety. The present paradigm differs from that in the sense that participants were instructed to sequentially consume the test drink in a signaled exposure procedure. One might argue that this atypical paradigm explains the absence of a flavour intensity effect. However, this alternative explanation is unlikely. Though somewhat atypical, repeated exposure to a test food/drink is not an entirely uncommon procedure and is known to render SSS; that is, a decline in pleasantness from the test food relative to other unconsumed food items [e.g. 7,20]. This paradigm also rendered significant SSS in both experiments of the current study. If flavour intensity would affect SSS with a different SSS paradigm, the present results at the very least show that manipulations of flavour intensity do not necessarily affect SSS.

Apart from the sequential consumption, the present SSS paradigm differed from a more traditional SSS paradigm in the sense that participants were instructed to consume a specific and fixed amount of lemonade according to online instructions provided by the experimenter. The volume of the test drink was smaller than participants would have drunk when having received the instruction to drink the lemonade until satiety. This procedure, of course, is very different from regular consumption and thus one may wonder to what degree the present pattern of results applies to such real world consumption. However, as the volume of the test drink in the present study was smaller than ad libitum intake, it is highly unlikely that the absence of a clear difference between groups in both experiments is due to participants having to drink an amount greater than they would normally choose to drink. Furthermore, it is unlikely that the absence of a clear difference between the groups is due to the volume of the test drink being too small to render strong SSS and hence potential differences in SSS. Previous research has shown that clear and strong SSS (i.e. a decline in pleasantness ratings) can be achieved with repeated intake of mere droplets of a certain test drink [21], or even with mere exposure to a given test food or drink [see 6,7,9].

It should be noted that the differences in flavour intensity of the test drinks in the present experiments were achieved by adding varying amounts of lemonade syrup to water, leading to differences in both taste and sweetness intensity. One might argue that this manipulation of sweetness intensity confounded results from Experiment 2 in which we manipulated flavour intensity by a series of gradually increasing or decreasing intensities of the strawberry lemonade drink. Generally speaking, sweeter drinks are often better liked. Decreasing sweetness intensity would thus promote the development of SSS and this renders the absence of a clear difference in SSS between this group and the group that did not receive any changes in sweetness intensity of the test drink as impossible to interpret unequivocally. In this case it is possible that SSS is unaffected by changes in flavour intensity, but it is also possible that the decrease in sweetness intensity masked a potential effect of flavour intensity on SSS. However, if the decreasing sweetness intensity would have masked otherwise less pronounced SSS in the group of participants receiving lemonade of decreasing sweetness intensity, then one would have expected to observe a clear difference between this group and the group of participants receiving the lemonade with increasing intensity. No such a difference was found though, and thus the absence of any significant differences in the degree and rate of SSS between the three groups in Experiment 2 corroborates the main conclusion that this manipulation of flavour intensity also does not affect SSS.

Of course one might argue that the intensity manipulations in the present study simply were not strong enough to have any effect on SSS. Note that in both experiments participants were able to discriminate the different flavour intensities of the test drink. But in Experiment 1, for example, the participants did not evaluate pleasantness of the high- and low-intensity test drinks differently; lending credence to the possibility that these test drinks did not sufficiently differ from one another in terms of intensity to exert any differential effect on SSS. If that were true though, the present pattern of results still shows that clearly noticeable differences in flavour intensity do not necessarily have any effect on the degree and rate of development of SSS. In other words, with regard to SSS, insofar an intensity effect exists at all, it is likely to be small and subtle.

\section{References}

[1] Rolls BJ. Sensory-specific satiety. Nutr Rev 1986;44:93-101.

[2] Hetherington M, Rolls BJ, Burley VJ. The time course of sensory-specific satiety. Appetite 1989;12:57-68.

[3] Miller DL, Bell EA, Pelkman CL, Peters JC, Rolls BJ. Effects of dietary fat, nutrition labels, and repeated consumption on sensory-specific satiety. Physiol Behav 2000;71:153-8.

[4] Bell EA, Roe LS, Rolls BJ. Sensory-specific satiety is affected more by volume than by energy content of a liquid food. Physiol Behav 2003;78:593-600.

[5] Hetherington M, Rolls BJ. Sensory-specific satiety in anorexia and bulimia nervosa. Ann NY Acad Sci 1989;575:387-98.

[6] Rolls ET, Rolls JH. Olfactory sensory-specific satiety in humans. Physiol Behav 1997;61:461-73.

[7] Smeets AJPG, Westerterp-Plantenga MS. Oral exposure and sensory-specific satiety. Physiol Behav 2006;89:281-6.

[8] Rolls ET. Taste, olfactory, and food texture processing in the brain, and the control of food intake. Physiol Behav 2005;85:45-56.

[9] Rolls ET, Rolls BJ, Rowe EA. Sensory-specific and motivation-specific satiety for the sight and taste of food and water in man. Physiol Behav 1983;30:185-92.

[10] Swithers SE, Hall WG. Does oral experience terminate ingestion? Appetite 1994;23:113-38

[11] Essed NH, van Staveren WA, Kok FJ, Ormel W, Zeinstra G, de Graaf C. The effect of repeated exposure to fruit drinks on intake, pleasantness and boredom in young and elderly adults. Physiol Behav 2006;89:335-41.

[12] Vickers Z, Holton E. A comparison of taste test ratings, repeated consumption, and post consumption ratings of different strengths of iced tea. J Sens Stud 1998;13:199-212.

[13] Maier A, Vickers Z, Inman JJ. Sensory-specific satiety, its crossovers, and subsequent choice of potato chip flavors. Appetite 2007;49:419-28.

[14] Havermans RC, Janssen T, Giesen JCAH, Roefs A, Jansen A. Food liking, food wanting, and sensory-specific satiety. Appetite 2009;52:222-5. 
[15] Hetherington MM, Rolls BJ. Sensory-specific satiety: theoretical frameworks and central characteristics. In: Capaldi ED, editor. Why we eat what we eat: The psychology of eating. Washington, DC: APA; 1996. p. 267-90.

[16] Wisniewski L, Epstein LH, Caggiula AR. Effect of food change on consumption, hedonics, and salivation. Physiol Behav 1992;52:21-6.

[17] Rolls BJ, van Duijvenvoorde PM, Rolls ET. Pleasantness changes and food intake in a varied four-course meal. Appetite 1984;5:337-48.

[18] Hetherington MM, Foster R, Newman T, Anderson AS, Norton G. Understanding variety: tasting different foods delays satiation. Physiol Behav 2006;87:263-71.
[19] Siep N, Roefs A, Roebroeck A, Havermans R, Bonte ML, Jansen A. Hunger is the best spice: an fMRI study of the effects of attention, hunger and calorie content on food reward processing in the amygdala and orbitofrontal cortex. Behav Brain Res 2009;198:149-58

[20] Brunstrom JM, Mitchell GL. Effects of distraction on the development of satiety. Br J Nutr 2006;95:761-9.

[21] Epstein LH, Rodefer JS, Wisniewski L, Caggiula AR. Habituation and dishabituation of human salivary response. Physiol Behav 1992;51:945-50. 